“ (C) 2017 IEEE. Personal use of this material is permitted. Permission from IEEE must be obtained for all other uses, in any current or future media, including

reprinting/republishing this material for advertising or promotional purposes, creating new collective works, for resale or redistribution to servers or lists, or reuse of any copyrighted component of this work in other works." 


\title{
Parameter Matching and Structure Optimal Design of a Brushless DC Motor for a Battery Electric Vehicle
}

\author{
Zhou Shi ${ }^{1}$, Xiaodong Sun ${ }^{1,2 *}$, Long $\mathrm{Chen}^{2}$, Zebin Yang ${ }^{3}, \mathrm{Ke} \mathrm{Li}^{3}$, Jianguo Zhu ${ }^{4}$, and Youguang $\mathrm{Guo}^{4}$ \\ 1 School of Automobile and Traffic Engineering, Jiangsu University, Zhenjiang 212013, China, xdsun@ujs.edu.cn \\ 2 Automotive Engineering Research Institute, Jiangsu University, Zhenjiang 212013, China \\ 3 School of Electrical and Information Engineering, Jiangsu University, Zhenjiang 212013, China \\ 4 School of Electrical, Mechanical and Mechatronic Systems, University of Technology, Sydney, Sydney, NSW 2007, Australia
}

\begin{abstract}
Calculation and matching of the main parameters of a brushless DC (BLDC) motor for a Battery electric vehicle $(\mathrm{EV})$ is studied in this paper. Usually, different shapes of permanent magnet (PM) and different magnetizing methods will affect the performance of the motor. Especially when the motor is designed for an $\mathrm{EV}$, more elements need to be considered, such as efficiency under normal operating conditions and torque ripple. So in this paper the performance of PMs with different shapes and different magnetizing methods will be compared by finite element analysis (FEA). Finally, the structure of the stator and rotor will also be optimized to obtain the required prototype model.
\end{abstract}

\section{INTRODUCTION}

Increasingly concerning about our environment and energy sources, there is a rapid growth of interests on electric vehicles (EVs) and hybrid electric vehicles (HEVs) from the society. Electric power is very important for EVs and HEVs [1-3]. It is an urgent need for research and development of advanced electric drive system for EVs. Among all types of motor drives, the brushless DC (BLDC) motor is the most attractive motor drive for EV so far. High power density and high efficiency are their notable features, which are attributed to the use of high-energy permanent magnet (PM) material. In EV applications, the motor has to be capable of providing enough torque when accelerating. At the same time the efficiency under normal operating conditions must be high enough to save energy and must ensure the heat dissipating capability $[4,5]$. In this paper the main parameters of the BLDC motor will be calculated by the parameters of the EV in section II. In section III, different types of PMs with different shapes and directions of magnetization were studied under no-load and load conditions by finite element analysis (FEA) to choose the suitable PM type for the proposed motor [6,7]. The conclusion is shown in section IV.

\section{PARAMETER MATCHING}

For conventional gasoline-powered vehicles, the power is transmitted from the engine to the wheels. For EVs, batteries output electrical energy to the motor, and then the motor generates a driving force to drive the vehicle $[8,9]$. So in every moment the power of the motor is always equal to the power consumption of mechanical transmission power loss and all resistance to motion. Vehicle driving resistance can be acquired though the calculations of the EV parameters which can be get from the test EV shown in Fig. 1. And the parameter values of the test EV are given in Table I.

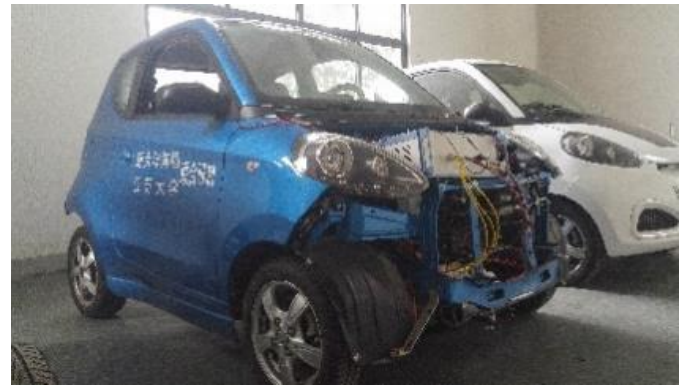

Fig. 1 Test EV.

TABLE I

The PARAMETER VALUES OF THE TeST EV

\begin{tabular}{|c|c|c|}
\hline Parameters & Symbol & Value \\
\hline Total mass of the EV & $M$ & $900 \mathrm{~kg}$ \\
\hline Front cross sectional area & $A$ & $2.1 \mathrm{~m}^{2}$ \\
\hline Air drag coefficient & $C_{D}$ & 0.34 \\
\hline Rolling friction coefficient & $f$ & 0.015 \\
\hline Radius of wheel & $R$ & $275 \mathrm{~mm}$ \\
\hline Final drive fixed gear ratio & $i_{\text {diff }}$ & 8.83 \\
\hline
\end{tabular}

According to the above theory, when the EV is running at a constant speed on a horizontal road, the power of the motor $\left(P_{e}\right)$ can be expressed as follow

$$
P_{\mathrm{e}}=\frac{1}{\eta_{T}}\left(\frac{G f u_{a}}{3600}+\frac{C_{D} A u_{a}}{76140}\right)
$$

where $\eta_{T}$ is the mechanical efficiency of transmission system, $G$ is the total gravity of the $\mathrm{EV}, f$ is the rolling friction coefficient, $C_{D}$ is the air drag coefficient, and $A$ is the front cross sectional area. In the case of having $P_{e}$ and $u_{a}$, the torque $\left(T_{t q}\right)$ and rotational speed $(n)$ required by the motor at a certain $u_{a}$ can be given by

$$
\begin{gathered}
u_{a}=0.377 \frac{r n}{i_{g} i_{0}} \\
P_{e}=\frac{T_{t q} n}{9550}
\end{gathered}
$$

where $r$ is the radius of the wheel and the $i_{g}$ is the transmission ratio. The main parameters of the motor can be calculated by the parameters in Table I and are given in Table II.

TABLE II

MAIN PARAMETERS OF THE BLDC

\begin{tabular}{|c|c|}
\hline Parameters & Value \\
\hline Work Voltage & $300 \mathrm{~V}$ \\
\hline Rate/ Peak Power & $6 / 18 \mathrm{kw}$ \\
\hline Max Torque & $90 \mathrm{~N} \cdot \mathrm{m}$ \\
\hline Max Rotating Speed & $4200 \mathrm{r} / \mathrm{min}$ \\
\hline
\end{tabular}


TABLE III

INITIALIZATION OF BLDC MOTOR DESIGN

\begin{tabular}{|c|c|}
\hline Phase number & 3 \\
\hline Pole number & 8 \\
\hline Slot number & 24 \\
\hline Stator outside diameter & $154 \mathrm{~mm}$ \\
\hline Rotor diameter & $101 \mathrm{~mm}$ \\
\hline Shaft diameter & $31.5 \mathrm{~mm}$ \\
\hline Air-gap length & $0.5 \mathrm{~mm}$ \\
\hline Core length & $134 \mathrm{~mm}$ \\
\hline Slot-fill factor & 0.68 \\
\hline Lamination material & MG19-29G \\
\hline PM material & $\mathrm{NdFe} 35$ \\
\hline
\end{tabular}

\section{BLDC Optimal DESIGN}

Here the BLDC motor is designed for a certain operation, the required size and weight should be designed properly for the test EV. At the same time, in order to match the speed of the motor and wheels, good coordination of the motor and transmission system should be put into consideration. On the basis of the specifications, the geometric dimensions and parameters of this motor can be initialized as listed in Table III.

In several topologies of the BLDC, the rotor PMs type BLDC topologies are under widespread application. According to the different arrangements of PMs in the rotor, they can further be classified as surface-mounted, surfaceinset, interior-radial and interior-circumferential topologies. In recent years, the research of interior-radial is the most popular type, since the PMs are mechanically protected, and it allows for a high-speed operation. In addition, due to its $d$ $q$ saliency, a reluctance torque exists [10, 11]. However, considering the high cost of interior-radial structure and the complex manufacturing process, it is not so suitable for the miniature battery electric vehicle which is studied in this paper. Thanks to the lower manufacturing costs the surfacemounted PM structure is chosen for the test EV here.

In order to save the cost of motor manufacturing, the most important thing is to make sufficient utilization of PMs materials as the material cost of PM materials is quite expensive. The design of the shape of the PM materials will affect the performance of the motor and the economy of the motor. So the design of PM shapes and magnetization methods is of great importance. Different types of PM shapes are shown in Fig. 2. The influence of two kinds of PM shapes with parallel and radial directions of magnetization on the air gap flux density, cogging torque, core loss, output torque and torque ripple is analyzed by FEA. For aesthetics of description, two shapes of PMs are defined as type 1 and type 2 . Both type 1 and type 2 are all surface-mounted while their shapes are different and type 1 is radially magnetized while type 2 is parallel magnetized. To study the motor performance with different PM shapes and magnetization directions the volumes of these two types are exactly the same. In addition to the shape of PM and different directions of magnetization, the other parameters and dimensions of the motors are exactly the same.

The FEA is used to obtain the simulation results of the magnetic field lines in different directions [12-14]. In the
FEA, two types of PM shapes were established and their magnetization directions were defined in different ways. From Fig. 3, the simulation results show that the distribution of magnetic field lines is consistent with the directions of magnetization directions defined in Fig. 2.

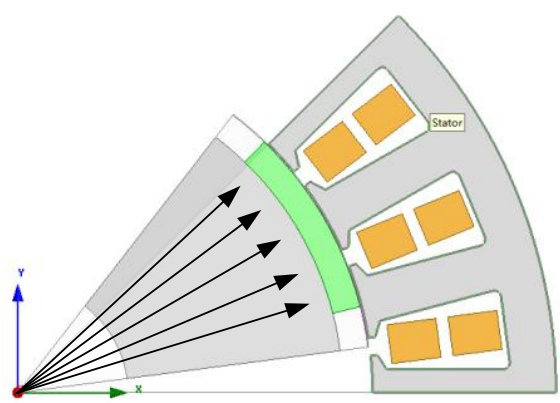

(a) Type 1(Radial magnetization)

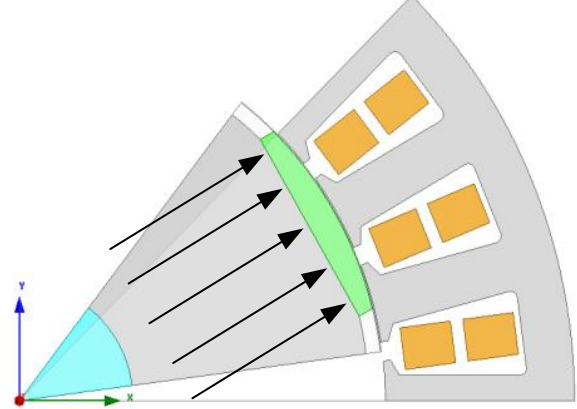

(b) Type 2 (Parallel magnetization)

Fig. 2 Different types of PM shapes with different magnetization directions.

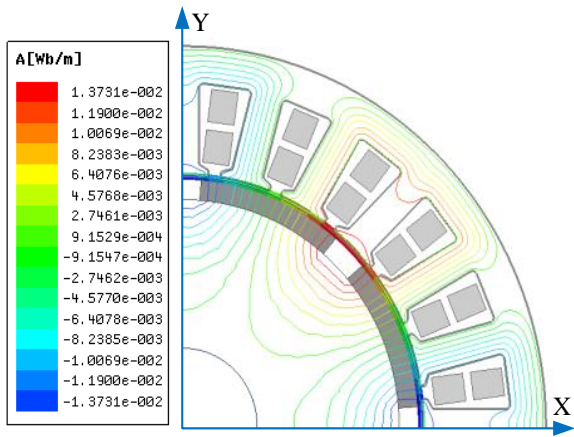

(a)

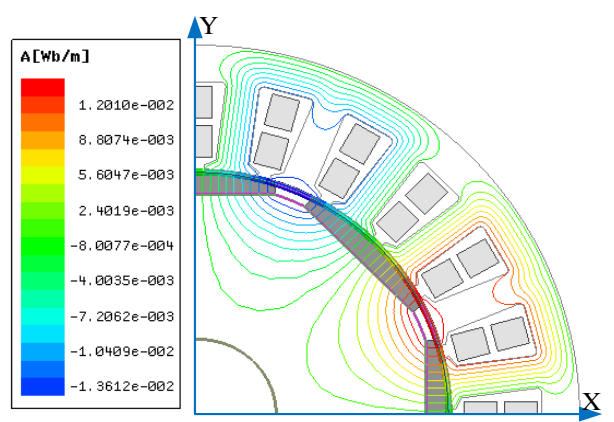

(b)

Fig. 3 Simulation results of magnetic field lines in different magnetizing directions (a) Type 1 (b) Type 2

With the exception of the difference in the PM shapes and magnetization directions, rotors and stators of two types of the BLDC are almost the same, so the air gap flux densities of two different types are close, which is matched with the diagram shown in Fig. 4. However, as the odd harmonic amplitudes from the one to eleven orders shown in 
Fig. 5 respectively, it can be seen that the figure for fundamental wave of type 2 is $5 \%$ higher than that of type 1 and the figure for 3 rd harmonic of type 2 is obviously lower than that of type1.

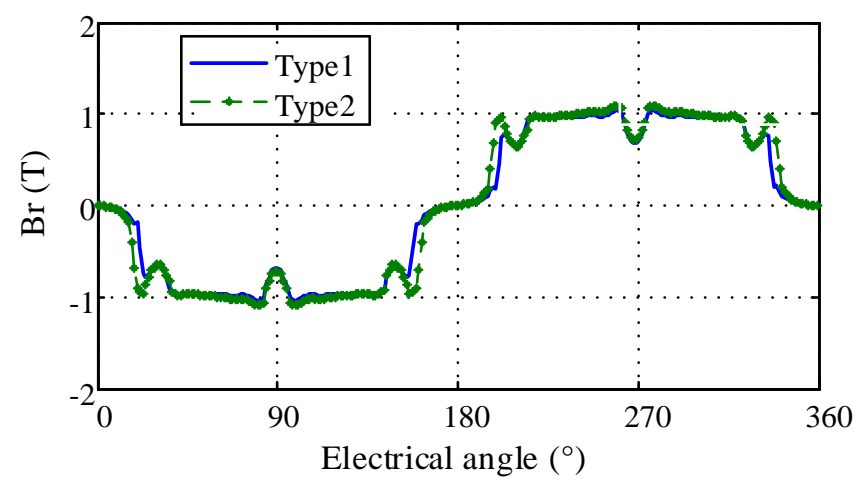

Fig. 4 Permanent magnetic airgap flux density.

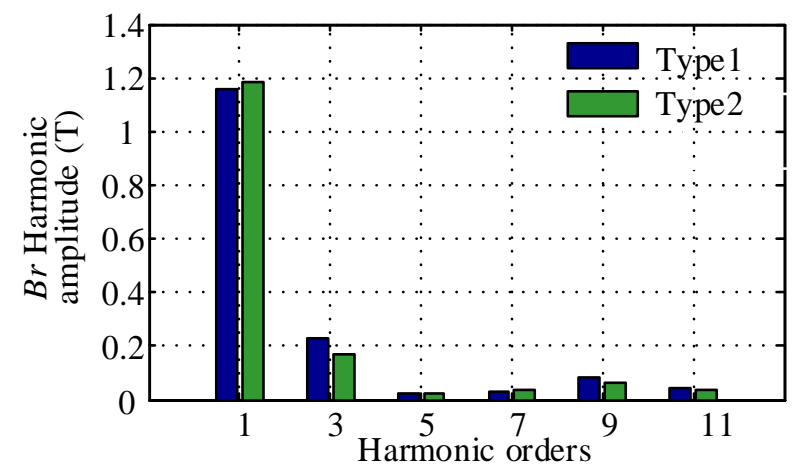

Fig. 5 FFT analysis to $B r$.

Higher air gap flux density means better torque output performance. From this point of view, type 2 is better than type1. In order to ensure smooth operation of the EV motor, the cogging torques of two different types shown in Fig. 5 are also analyzed. It can be seen from the Fig.5 that the amplitudes of cogging torque of type 1 is $28 \%$ higher than that of type 2 .

Through the above FEA, type 2 has better electromagnetic characteristics and lower cogging torque. From the above analysis, it can be concluded that type 2 with parallel direction of magnetization has better static performance.

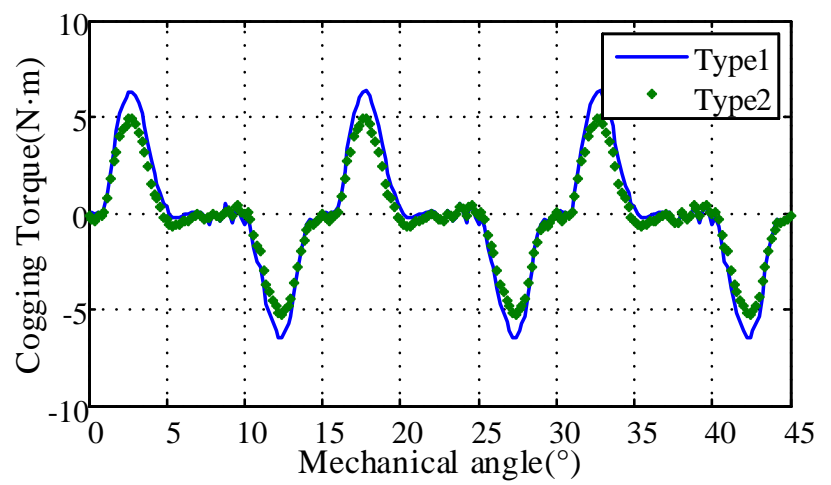

Fig. 6 Simulation results of cogging torque.

The analysis and comparison of two PM shapes under no-load conditions have been stated above. In the same way, the characteristics of two PM types under load are also analyzed and compared $[15,16]$. The Maxwell 2D module of the ANSYS software is used to analyze the performance of the two types under the effective current of $8 \mathrm{~A}$. The core loss of the two different types is shown in Fig. 7. In order to obtain the value of core loss in steady operation, the average value of iron loss from $10 \mathrm{~ms}$ to $20 \mathrm{~ms}$ is calculated. Average core loss of type 1 is $67.9 \mathrm{w}$ which is $5.4 \%$ higher than that of type2.

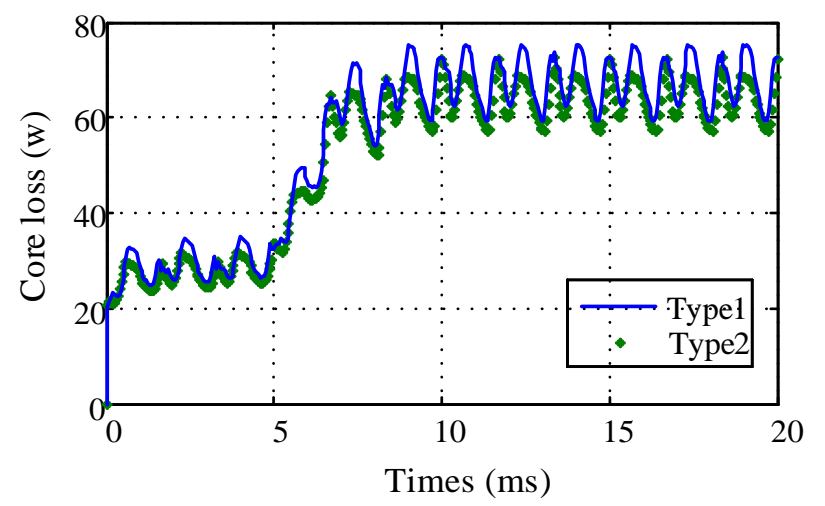

Fig. 7 Core loss.

The output torques of the two different types are shown in Fig. 8. It can be seen from Fig. 8 that the torque ripple of type 2 is obviously smaller than that of type1. Besides, the average torque of type 2 under the effective current of $8 \mathrm{~A}$ is $15.6 \mathrm{~N} \cdot \mathrm{m}$ which is also higher than that of type 1 which is $15.1 \mathrm{~N} \cdot \mathrm{m}$. That means type2 PM shape with parallel direction of magnetization not only has higher output torque but also limits the torque ripple.

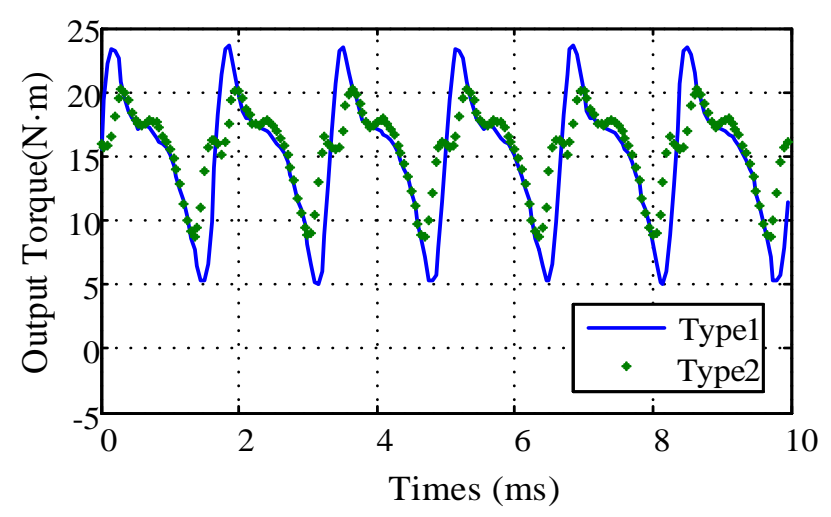

Fig. 8 Output torque.

Based on the above study of two PM shapes with different magnetization methods, type 2 is more suitable for the design with lower core loss and smoother output torque.

Apart from the shapes and the magnetization methods of PM, the structure of stator and rotor cold-rolled silicon steel sheet will seriously affect the performance of the motor. Especially the structure of the stator slot includes the stator slot opening length, the groove depth, and the tooth wide will affect the cogging torque, torque output capability and core loss. On the basis of ensuring the groove area, the parameters are optimized synthetically. In addition, optimizing the structure of the rotor can not only improve the electromagnetic characteristics of the motor, but also reduce the mass of the rotor which will improve the response characteristics of the motor [17], which is of great significance to the use of motors in EV. Finally the specific 
dimensions of the motor are shown in table IV, and the exploded diagram of prototype motor is shown in Fig. 9.

TABLE IV

OPTIMIZED STATOR AND ROTOR DIMENSIONS

\begin{tabular}{|c|c|c|c|}
\hline \multicolumn{2}{|c|}{ STATOR DATA } & \multicolumn{2}{c|}{ ROTOR DATA } \\
\hline $\begin{array}{c}\text { Outer Diameter } \\
\text { of Stator }(\mathrm{mm})\end{array}$ & 154 & $\begin{array}{c}\text { Minimum Air Gap } \\
(\mathrm{mm})\end{array}$ & 1.2 \\
\hline $\begin{array}{c}\text { Inner Diameter } \\
\text { of Stator }(\mathrm{mm})\end{array}$ & 102.2 & $\begin{array}{c}\text { Inner Diameter } \\
(\mathrm{mm})\end{array}$ & 31.5 \\
\hline $\begin{array}{c}\text { Stator Slot } h s 0 \\
(\mathrm{~mm})\end{array}$ & 1.1 & $\begin{array}{c}\text { Polar Arc Radius } \\
(\mathrm{mm})\end{array}$ & 50.5 \\
\hline $\begin{array}{c}\text { Stator Slot } h s 2 \\
(\mathrm{~mm})\end{array}$ & 15.56 & $\begin{array}{c}\text { Mechanical Pole } \\
\text { Embrace: }\end{array}$ & 0.8 \\
\hline $\begin{array}{c}\text { Stator Slot } b s 0 \\
(\mathrm{~mm})\end{array}$ & 2.6 & $\begin{array}{c}\text { Electrical Pole } \\
\text { Embrace: }\end{array}$ & 0.78 \\
\hline $\begin{array}{c}\text { Stator Slot } b s 1 \\
(\mathrm{~mm})\end{array}$ & 8.3 & $\begin{array}{c}\text { Width of Magnet } \\
(\mathrm{mm})\end{array}$ & 31.21 \\
\hline $\begin{array}{c}\text { Stator Slot } b s 2 \\
(\mathrm{~mm})\end{array}$ & 12.36 & $\begin{array}{c}\text { Stacking Factor of } \\
\text { Iron Core: }\end{array}$ & 0.64 \\
\hline $\begin{array}{c}\text { Tooth Width } \\
(\mathrm{mm})\end{array}$ & 5.8 & PM Weight $(\mathrm{kg})$ & 1.04 \\
\hline $\begin{array}{c}\text { Stator Core Steel } \\
\text { Weight }(\mathrm{kg})\end{array}$ & 6.05 & $\begin{array}{c}\text { Rotor Core Steel } \\
\text { Weight }(\mathrm{kg})\end{array}$ & 3.74 \\
\hline
\end{tabular}

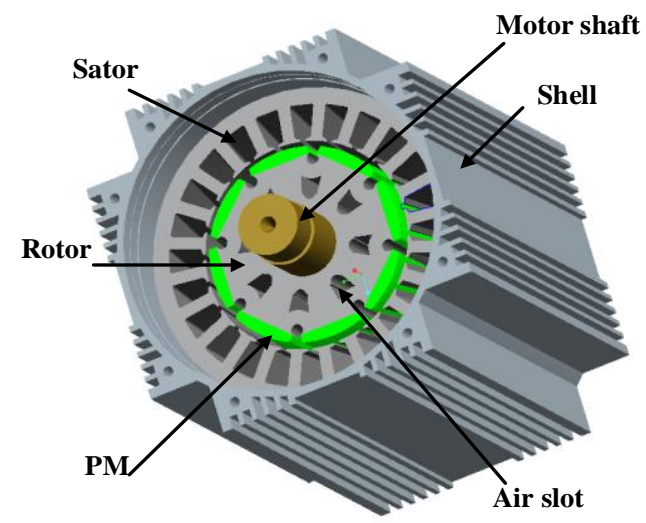

Fig. 9 Exploded diagram of prototype motor.

\section{CONCLUSION}

The parameters of the test EV are measured in order to be used to calculate the requirements of the drive motor. The main parameters of the BLDC were calculated by the parameters of the EV in this paper. Different types of PMs with different magnetization methods were studied by FEA. Through the electromagnetic analysis of different PM structures under no-load and load conditions, a more suitable PM structure with parallel direction of magnetization was chosen for design. Finally the stator and rotor structures were also optimized. Further studies, including real EV testing will be continued in the next step.

\section{ACKNOWLEDGMENT}

This work was supported by the National Natural Science Foundation of China (51305170 and 51475214), the Natural Science Foundation of Jiangsu Province of China (BK20170071 and BK20141301), the Key Project of Natural Science Foundation of Jiangsu Higher Education Institutions (17KJA460005), the China Postdoctoral Science Foundation (2016M601726 and 2015T80508), the Six Categories Talent Peak of Jiangsu Province (2015-XNYQC003, 2014-ZBZZ-017, and 2016-GDZB-096), Zhenjiang Key Research and Development Project (GY2016003), the
"333 project" of Jiangsu Province (BRA2017441), the Postgraduate Research \& Practice Innovation Program of Jiangsu Province (KYCX17_1815), and the Priority Academic Program Development of Jiangsu Higher Education Institutions (PAPD).

\section{REFERENCES}

[1] K. T. Chau, C. C. Chan and C. Liu, "Overview of permanent-magnet brushless drives for electric and hybrid electric vehicles," IEEE Transactions on Industrial Electronics, Vol. 55, NO. 6, JUNE 2008 pp. $2246-2257$

[2] S. K. Kommuri, M. Defoort, H. R. Karimi and K. C. Veluvolu, "A robust observer-based sensor fault-tolerant control for pmsm in electric vehicles," IEEE Transactions on Industrial Electronics, Vol. 63, NO. 12, DECEMBER 2016 pp.7671-7681

[3] X. Sun, Z. Shi, L. Chen, and Z. Yang, "Internal model control for a bearingless permanent magnet synchronous motor based on inverse system method," IEEE Transactions on Energy Conversion, 2016, 31(4): 1539-1548.

[4] K. Ahn, A. E. Bayrak and P. Y. Papalambros, "Electric vehicle design optimization: integration of a high-fidelity interior-permanent-magnet motor model," IEEE Transactions on Vehicular Technology, vol. 64, pp. 3870-3877, 2015.

[5] X. Sun, L. Chen, H. Jiang, Z. Yang, J. Chen, and W. Zhang. "Highperformance control for a bearingless permanent magnet synchronous motor using neural network inverse scheme plus internal model controllers," IEEE Transactions on Industrial Electronics, 2016, 63(6): 3479-3488.

[6] G. Lei, Y. G. Guo, J. G. Zhu, X. M. Chen, and W. Xu, "Sequential subspace optimisation method for electromagnetic devices design with orthogonal design technique," IEEE Transactions on Magnetics, vol. 48, no. 2, pp. 479-482, 2012.

[7] X. Sun, B. Su, L. Chen, Z. Yang, X. Xu, and Z. Shi, "Precise control of a four degree-of-freedom permanent magnet biased active magnetic bearing system in a magnetically suspended direct-driven spindle using neural network inverse scheme," Mechanical Systems and Signal Processing, 2017, 88: 36-48.

[8] K. Ahn, A. E. Bayrak and P. Y. Papalambros, "Electric vehicle design optimization: integration of a high-fidelity interior-permanent-magnet motor model," IEEE Transactions on Vehicular Technology, vol. 64 , pp. 3870-3877, 2015.

[9] P. H. Nguyen, E. Hoang and M. Gabsi, "Performance synthesis of permanent-magnet synchronous machines during the driving cycle of a hybrid electric vehicle," IEEE Transactions on Vehicular Technology, vol. 60, pp. 1991-1998, 2011.

[10] X. Sun, L. Chen, Z. Yang, "Overview of bearingless permanent magnet synchronous motors," IEEE Transactions on Industrial Electronics, 2013, 60(12): 5528-5538.

[11] S. S. Williamson, A. Emadi and K. Rajashekara, "Comprehensive efficiency modeling of electric traction motor drives for hybrid electric vehicle propulsion applications," IEEE Transactions on Vehicular Technology, vol. 56, pp. 1561-1572, 2007

[12] G. Lei, G. Y. Yang, K. R. Shao, Y. G. Guo, J. G. Zhu, and J. D. Lavers, "Electromagnetic device design based on RBF models and two new sequential optimisation strategies," IEEE Transactions on Magnetics, Vol. 46, No. 8, pp. 3181-3184, 2010.

[13] W. Hua, H. Zhang, M. Cheng, J. Meng, and C. Hou, "An outer-rotor flux-switching permanent-magnet-machine with wedge-shaped magnets for in-wheel light traction," IEEE Transactions on Industrial Electronics, vol. 64, pp. 69-80, 2017.

[14] G. Lei, C. C. Liu, J. G. Zhu, and Y. G. Guo, "Multilevel robust design optimization of a superconducting magnetic energy storage based on a benchmark study," IEEE Transactions on Applied Superconductivity, vol. 26, no. 7, Oct. 2016, Art. no. 5701405.

[15] G. Lei, K. R. Shao, Y. G. Guo, J. G. Zhu, J. D. Lavers, "Improved sequential optimisation method for high dimensional electromagnetic optimisation problems," IEEE Transactions on Magnetics, Vol. 45, No. 10, pp. 3993-3996, 2009

[16] C. Jeong and J. Hur, "A novel proposal to improve reliability of spoke-type BLDC motor using ferrite permanent magnet," IEEE Transactions on Industry Applications, vol. 52, pp. 3814-3821, 2016.

[17] X. Sun, L. Chen, Z. Yang, H. Zhu. "Speed-sensorless vector control of a bearingless induction motor with artificial neural network inverse speed observer," IEEE/ASME Transactions on Mechatronics, 2013, 18(4): 1357-1366. 